\title{
Integration of Virtual Patients in Education of Veterinary Medicine
}

\author{
Jaroslav Majerník \\ Pavol Jozef Šafárik University in \\ Košice, Faculty of Medicine, \\ Trieda SNP 1, Košice, Slovakia \\ Email: jaroslav.majernik@upjs.sk
}

\author{
Marián Mad'ar \\ University of veterinary medicine \\ and pharmacy in Košice, \\ Komenského 73, Košice, Slovakia \\ Email:madarmarian@gmail.com
}

\author{
Jana Mojžišová \\ University of veterinary medicine \\ and pharmacy in Košice, \\ Komenského 73, Košice, Slovakia \\ Email: jana.mojzisova@uvlf.sk
}

\begin{abstract}
Problem based learning, utilizing simulations and virtual reality tools represents one of the approaches integrated into the education of medicine to prepare medical students for both the bedside teaching and their later clinical praxis. On the other side, implementation of innovative didactic materials may be useful also for veterinary medicine students. Thus, veterinary topics can be introduced and explained in the form of virtual cases, helping students to understand relationships between theory and practical application of their decisions. Simulations and virtual cases are also used to assess students' clinical reasoning skills. Therefore, our work is aimed on integration of modern simulation tools into education process at University of veterinary medicine and pharmacy in Košice, Slovakia. Inspired by our colleagues from Faculty of Medicine in Košice and respecting our requirements we were able to specify appropriate methods and to introduce the first veterinary virtual patient to our students.
\end{abstract}

\section{INTRODUCTION}

$\mathrm{T}$ HE long history of education brought various attractive teaching and learning approaches. To reach the most effective and modern forms of education it is necessary to revise not only what we teach but also how we teach.

The failures resulting from inadequate competencies of medical and veterinary practitioners may lead to fatal consequences of their patients. To increase the competence of students as well as their clinical reasoning ability the problem based learning (PBL) methods are widely used. Using information and communication technologies (ICT), the former presentation of paper patient cases in PBL was enhanced by using multimedia content. Here, the virtual patients (VPs) were introduced as interactive electronic medical cases that offer advanced support for learning [1]. However, the primary aim of virtual patients is to simulate real patient care [2]. From the technical point of view, it represents an interactive computer based tool simulating medical practice $[3,4]$.

VPs are usually used to introduce clinical problems to the students, to begin education of medical cases or to evaluate students' medical knowledge. In most cases, the goal of the student is to find the right diagnosis and propose a correct medical treatment based on the presented data [5]. VPs are implemented to substitute appropriate real-life patients, connection between preclinical and clinical information and feedback about performance or decisions realized by learners. Natural advantage of VPs is a safe educational clinical environment where the students obtain first clinical experience as their decisions affect progress of the case and are equipped by expert's explanations. Using VPs, learners improve their clinical reasoning skills from their mistakes that increase the level of preparation for subsequent real interactions with live patients [6, 7].

Many areas of medical education already implemented certain forms of VPs into the curricula. These areas include surgery $[8,9]$, nursing care $[10,11]$, human behaviour [12], psychiatry [13], medical microbiology [14], pharmacy [15] and many others. However, VPs integrated into the curricula of veterinary medicine are rarely reported. One of the positive examples is the project vetVIP (Use of virtual problems/virtual patients in veterinary basic sciences) [16].

Considering the ways how the veterinary medicine curricula is delivered to our students and recent capabilities of modern teaching methods, we decided to integrate simulations of virtual cases into the courses of veterinary medicine. We expected positive impact on our students in the sense of their better preparation for later practical contact with veterinary patients. Our expectations were based on the surveys and results that were obtained by our colleagues from Faculty of Medicine in Košice, Slovakia, in teaching of medical students $[17,18]$. Thanks to their activities and cooperation within MEFANET network (Medical Faculties Network), which already brought many effective tools to support medical education in Czech Republic and Slovakia [19], we were able to identify the optimal platform and the ways how to integrate it into our curricula and thus to modernize education process of veterinary medicine.

\section{MATERIALS AND METHODS}

Our innovation activities started by the survey and needs analysis results of the CROESUS project [20]. This project brought PBL and VPs into the curricula of medical education at Masaryk University in Brno, Czech Republic and Pavol Jozef Šafárik University in Košice, Slovakia. Survey was oriented to identify requirements on VPs and ICT simulation platforms. The questions covered the topics related to current state of e-learning services used by educators, methods to assess students' knowledge and skills, preferred technologies and architectures, technical skills, 
current usage of VP systems (if any) and also the financial capabilities to operate VPs and/or VP platform.

$37(78,7 \%)$ of 47 respondents that participated in the survey stated that they do not use any VPs. However, $66 \%$ of all respondents want/plane to use VPs in their curricula. Responses in the survey resulted in the list of requirements for VPs and VP platforms. These users' requirements included: a) learning materials for students should be accessible anytime and almost anywhere, b) the system should offer various paths to the solution of the patient case and the user's decision should have and influence on how patient case unfolds, c) multimedia content should be supported by the system and easily integrated and/or modified in VP paths, d) content of VP should be created in the way which allows its reusability and standardization, e) system should offer tools for continuous assessment of students' knowledge, f) the whole system should be easily administered and adaptable to the infrastructure of existing learning courses if needed, g) functions, features and interface of the system should be intuitive and easy to use, and $\mathrm{h}$ ) based on academic environment and educational purpose it is expected the system will require minimal or no financial resources.

Respecting these teachers' requirements, we concluded the VP platform should support the following main features: a) branched structure, b) multimedia content, c) interoperability to exchange outputs, d) web administrative and web accessible environment, e) national or English localization and f) free/open license.

In the next analysis, we studied and summarized information about several recently available computer-based simulation programs/platforms designed and used in medical education. The list of platforms involved CAMPUS, CASUS, DecisionSim, OpenLabyrinth, RoD, TUSK, UChoose, VIC and WebSP. Comparing all available information, the systems were rated and they obtained one point if they had the required feature, half of the point if the feature was not as expected but acceptable and zero if the feature was not available at all. The final order of the systems was OpenLabyrinth (8.0), Tusk/OpenTusk (7.0), DecisionSim and Web-SP (6.5), UChoose (6.0), CAMPUS and CASUS (5.5), and RoD and VIC (3.5). Respecting results of this analysis, we decided to use OpenLabyrinth as a platform to simulate veterinary VPs.

OpenLabyrinth, used as a VP simulation platform is fully standards compliant and free open source software. It supports authoring and playing VPs in online environment. The principle of VP in Open Labyrinth is based on the map of global properties such as the map type (game, maze, algorithm, etc.), authors, real timers, visual appearance, scores, counters, etc. Within each map there are series of linked pages, named nodes, defining the options available to the user. In general, the node is the webpage presented to the user/student. Although a map may have just one node, typically it will consist of many interconnected nodes.

Individual nodes are interconnected by edges that represent potential decisions of the learner. Completing a case requires choices to be made at key scenario points with the consequences of these choices affecting the final path through the case. The virtual patients developed using Open Labyrinth are conforming with the MedBiquitous Virtual Patients Specifications.

\section{RESULTS}

To create a virtual case of veterinary patient, we have to note that there are essential differences comparing virtual patients developed for human medicine and medical students. Expecting that the VP is based on data of real cases, there is almost no problem to obtain anamnesis from human patients, but the verbal discussion with the veterinary patients is impossible.

To unfold problems or to identify place of pain, the veterinarian can consult only with owners of animals. Consultation between owner and veterinarian can significantly help to reveal diagnosis, because only the owner of animal can see the differences in behaviour of his/her animal. If the owner is no precise in monitoring, it can be a severe problem to obtain correct diagnosis - based on incomplete anamnesis. Then, the veterinarian can obtain exact diagnosis only using differential diagnostic methods and/or results of special diagnostic and clinical tests, for example haematology. Depending on location of the disease, the different diagnostic methods should be used, for example in case of corneal ulcer or in case of haemorrhagic diarrhoea. Special group of veterinary diagnosis is used in cases of infectious diseases, e.g. zoonoses or zooanthorpoones. Considering these facts, we prefer to integrate branched structures into VPs to force reasoning skills of our students.

After the OpenLabryinth (OL) was installed, using common web server running Apache, MySQL, and PHP, the pilot veterinary virtual patient was developed. Figure 1 shows individual nodes of VP as organized in visual editor.

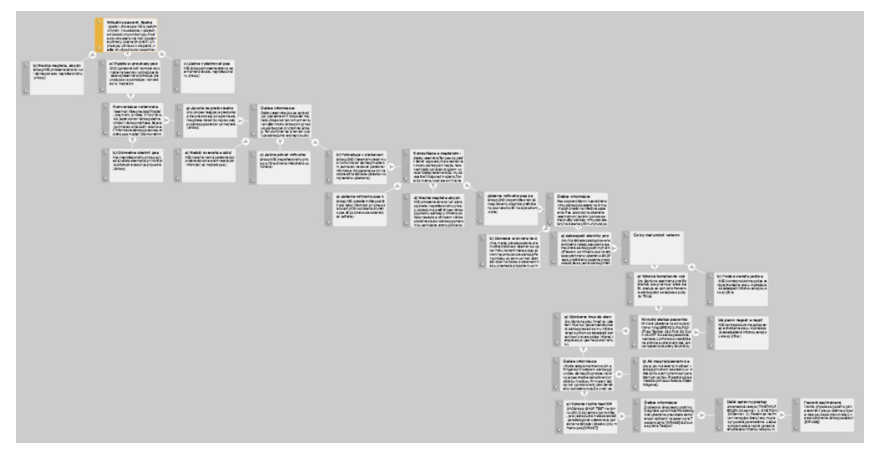

Fig. 1 VP nodes in OpenLabyrinth's Visual Editor.

The idea was to generate a highly representative case that will be used not only by the veterinary medicine students in education process, but also as a template and an exemplary case that will be presented to potential authors with the aim to increase their motivation, to reveal advantages of this approach and to minimize apprehensions that may arose from insufficient technical and ICT skills of veterinarians.

Figure 2 shows the root node of pilot VP case named Apathy. The recent sequence of the case consists of 30 nodes, in which the students are able to choose one of 


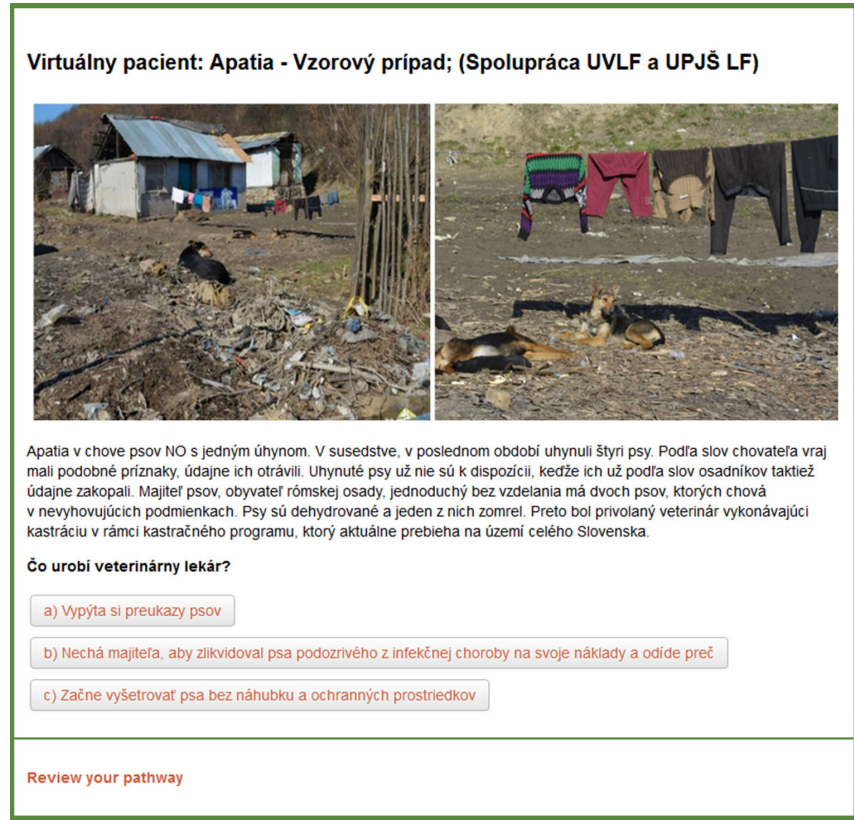

Fig. 2 First node of final pilot veterinary VP created in OpenLabyrinth.

usually three links to other nodes - decisions. The links are randomly ordered and correct and incorrect decisions are particularly commented. All the nodes have additional explanatory information to allow students to find supplementary study materials and to explain consequences of their decisions.

The pilot VP deals with diagnostics of parvoviruses in animals breeding in inconvenient conditions and in segregated gipsy communities. Such animals often cause the health risks not only for other animals living nearby these communities, but also for people living there. Except of educational background related to the topic, the case should also point out to the long-time problem of unbearable and uncontrolled reproduction of animals in such conditions. VP also highlighted the problems related to cruelty to animals, needs to regulate population of such animals, and considerable risks of infectious diseases occurrence. This topic was purposely selected, as there is a need of special patient care. At the beginning of the case, it is necessary to select the proper procedure of the veterinarian in given conditions. The problem related to anamnesis data and to incomplete documentation needed for breeding of animals, especially vaccination certificates of perished animals (dogs) is presented as well. Whole case is designed in the way, where, based on data from pathological and anatomical dissections of perished animals as well as on fast diagnostic method, the students are able to reveal if there is an infectious disease or not. The Snap test was used as fast diagnostic method. The procedures used to examine the presence of endoparasites in animals are also presented in VP structure. Finally, to make this pilot case the most complex one, the procedures of manipulation with infectious animals, methods to design best therapy depending on diagnosis and the draft of measures to prevent spreading of infection diseases in given breeding conditions were integrated into the explanatory parts of particular nodes.

The students are able to study the case everywhere as its link was shared for them through university webpage. Also, they are able to use any device as the VPs generated in OL are played using standard web browsers. Educational context is supported by various tools (multimedia, supporting information, comments, path review etc.) integrated directly in VPs. Our first students, that played this pilot VP, also appreciated existence of review pathway feature as it allows them to understand relations between individual decisions when they review their progress.

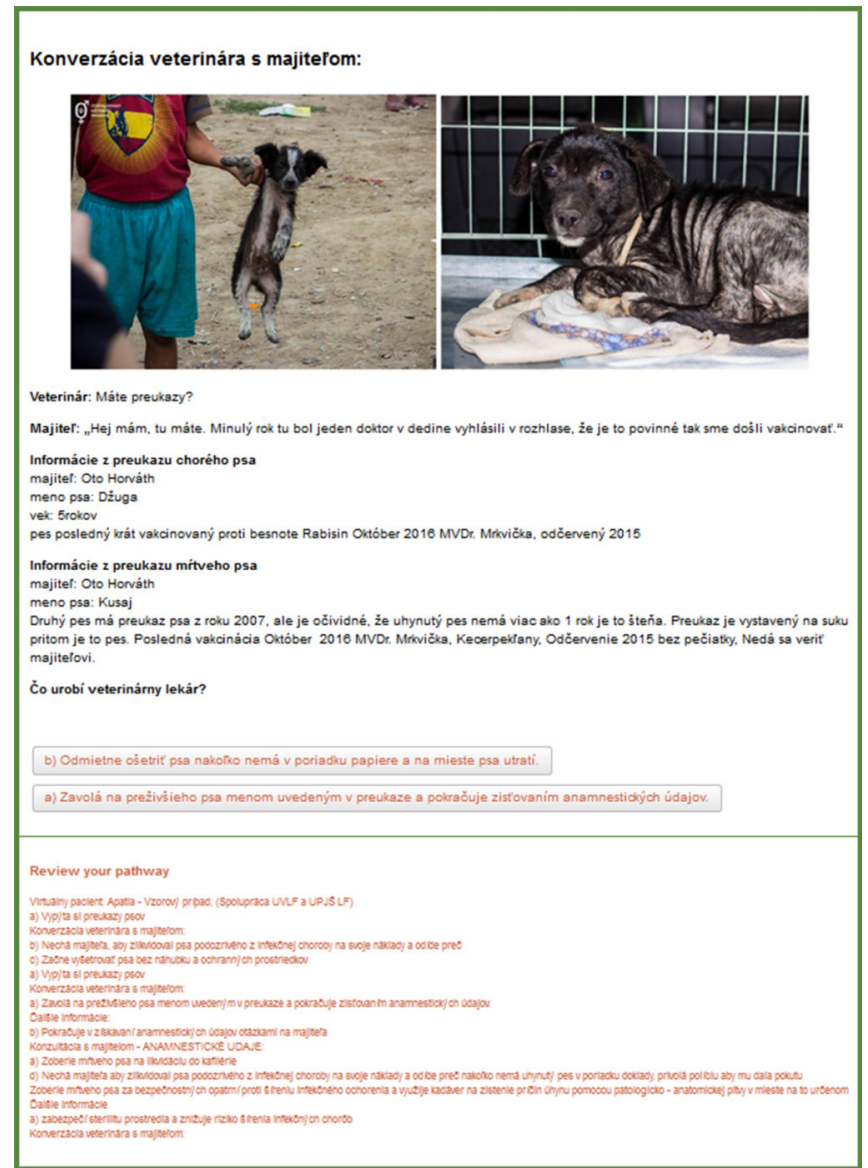

Fig. 3 Pathways checked by the students.

This first case, developed for veterinary medicine students at University of veterinary medicine and pharmacy in Košice, Slovakia, was accepted very well by the students as well as by the teachers. Both groups were positively surprised by the system and the way how relatively easily it can be created and applied into the pedagogical process. This pilot result convinced us to generate a series of VPs that will be aimed on various diseases and animals. Also, the final versions will be translated from Slovak to English to be able to use them in education of foreign students of veterinary medicine. 


\section{CONCLUSION}

Our effort is aimed to improve experience and intuition, as the most essential factors for clinical reasoning, in veterinary medicine students. Nowadays, majority of students use various devices to access electronic education resources, with no time and space limitation. Therefore, the VPs were recognized as modern and efficient tools that can be used in combination of traditional approaches to modernize our education process.

The first pilot veterinary medicine VP registered positive reactions from the students and they reported that they can feel responsibility for their decision, but everything in a safe environment. Also, they have to combine various clinical information before their decision is done and this is not only about memorizing and understanding of basic knowledge. Teachers were impressed by possibilities of this interactive approach too. They already suggested the topics and base structures of their new veterinary VPs including heavy, small and exotic animals.

Further complex analysis should be performed after new veterinary VPs will be finished and integrated into the education process. Then, the real impact on students' knowledge, skills and competences will be verified in an objective way.

\section{ACKNOWLEDGMENT}

Results presented in this work were obtained with the support of the national agency's grant KEGA 017UPJS4/2016 "Visualization of education in human anatomy using video records of dissections and multimedia teaching materials".

\section{REFERENCES}

[1] J. Donkers, D. Verstegen, B. de Leg, N. de Jong, "E-learning in problem-based learning", Chap. 13 in Lessons from Problem-based Learning, by H. J. M. van Berkel, New York: Oxford University Press, 2010, 117-128, http://dx.doi.org/10.1093/acprof:oso/ 9780199583447.003 .0013$.

[2] E. Duff, L. Miller, and J. Bruce, "Online Virtual Simulation and Diagnostic Reasoning: A Scoping Review", Clinical Simulation in Nursing, 2016, 12, pp. 377-384, http://dx.doi.org/10.1016/j.ecns. 2016.04.001

[3] A. J. Kleinheksel, "Transformative learning through virtual patient simulations: Predicting critical student reflections.", Clinical Simulation in Nursing, 2014, 10(6), e301-e308. http://dx.doi.org/ 10.1016/j.ecns.2014.02.001.

[4] J. Kubicek, T. Rehacek, M. Penhaker, M., I. Bryjova, "Software simulation of CT reconstructions and artifacts", Lecture Notes of the Institute for Computer Sciences, Social-Informatics and Telecommunications Engineering, LNICST, Volume 165, 2016, Pages 428-437, http://dx.doi.org/10.1007/978-3-319-29236-6_41.

[5] A.A. Kononowicz and I. Hege, "Virtual Patients as a Practical Realisation of the E-learning Idea in Medicine", Chap. 18 in E- learning Experiences and Future, by Safeeullah Soomro, 345-370. Rijeka: InTech. Accessed April 1, 2010, http://dx.doi.org/10.5772/ 8803.

[6] E. Forsberg, K. Ziegert, H. Hult, U. Fors, "Assessing progression of clinical reasoning through virtual patients: An exploratory study", Nurse Education in Practice, 2016, 16, pp. 97-103, http://dx.doi.org/ 10.1016/j.nepr.2015.09.006.

[7] M. Peddle, M. Bearman, D. Nestel, "Virtual Patients and Nontechnica Skills in Undergraduate Health Professional Education: An Integrative Review", Clinical Simulation in Nursing, 2016, 12, pp. 400-410, http://dx.doi.org/10.1016/j.ecns.2016.04.004.

[8] R. Kleinert, P. Plum, N. Heiermann, R. Wahba, D.H. Chang, A.H. Hölscher, and D.L. Stippel, "Embedding a Virtual Patient Simulator in an Interactive Surgical lecture", Journal of Surgical Education, 2016, 73 (3), pp. 433-441, http://dx.doi.org/10.1016/j.jsurg.2015.11. 006.

[9] K.M. McKendy, N. Posel, D.M. Fleiszer, and M.C. Vassiliou. "A Learner-Created Virtual Patient Curriculum for Surgical Residents: Successes and Failures", Journal of Surgical Education, 2016, 73 (4), pp. 559-566, http://dx.doi.org/10.1016/j.jsurg.2016.02.008.

[10] E. Forsberg, K. Ziegert, H. Hult, U. Fors, "Clinical reasoning in nursing, a think-aloud study using virtual patients - A base for an innovative assessment", Nurse Education Today, 34, 2014, pp. 538542, http://dx.doi.org/10.1016/j.nedt.2013.07.010

[11] P. Moule, K. Pollard, J. Armoogum, S. Messer, "Virtual patients: Development in cancer nursing education", Nurse Education Today, 2015, 35, pp. 875-880, http://dx.doi.org/10.1016/j.nedt.2015.02.009.

[12] A. Kleinsmith, D. Rivera-Gutierrez, G. Finney, J. Cendan, B. Lok, "Understanding empathy training with virtual patients", Computers in Human Behavior, 2015, 52, pp. 151-158, http://dx.doi.org/10.1016/ j.chb.2015.05.033.

[13] C. Sunnqvist K. Karlsson L. Lindell, U. Fors. "Virtual patient simulation in psychiatric care - A pilot study of digital support for collaborate learning", Nurse Education in Practice, 2016, 17, pp. 3035, http://dx.doi.org/10.1016/j.nepr.2016.02.004.

[14] D. McCarthy, C. O'Gorman, and G.J. Gormley, "Developing virtual patients for medical microbiology education", Trends in Microbiology, 2013, Vol. 21, No. 12, pp. 613-615, http://dx.doi.org/10.1016/j.tim.2013.10.002.

[15] E. Menendeza, B. Balisa-Rochab, M. Jabbur-Lopesb, W. Costaa, J.R Nascimentoa, M. Dóseaa, L. Silva, D.L. Junior, "Using a virtual patient system for the teaching of pharmaceutical care", International Journal of Medical Informatics, 2015, 84, pp. 640-646, http://dx.doi.org/10.1016/j.ijmedinf.2015.05.015.

[16] M. Kankofer, W. Kedzierski, J. Wawrzykowski, M. Adler, M. Fischer and J.P. Ehlers, "Use of virtual problems in teaching veterinary chemistry in Lublin (Poland)", Veterinary Medicine Austria 103 (5), 2016, pp. 125-131.

[17] J. Majernik, L. Szerdiová, D. Schwarz, J. Zivcak, "Integration of virtual patients into modernizing activities of medical education across MEFANET", IDT 2016, pp. 186-189, http://dx.doi.org/ 10.1109/DT.2016.7557171

[18] J. Živčák, R. Hudák, T. Tóth, "Rat skin wounds tensile strength measurements in the process of healing", IEEE 10th Jubilee International Symposium on Applied Machine Intelligence and Informatics, SAMI 2012 - Proceedings, 6208996, pp. 389-392.

[19] D. Schwarz, P. Štourač, M. Komenda, H. Harazim, M. Kosinová, J. Gregor, R. Hůlek, O. Smékalová, I. Křikava, R. Štoudek, L. Dušek, "Interactive algorithms for teaching and learning acute medicine in the Network of Medical Faculties MEFANET, Journal of Medical Internet Research, 2013, 15 (7), art. no. e135. http://dx.doi.org/10. 2196/jmir. 2590 .

[20] J. Majernik, D. Schwarz, "Virtual Patient Simulation Platform for CROESUS and MEFANET", Trends of education and research in biomedical technologies, Košice, 2016, ISBN 9788081524707, pp. 84-90. 